\title{
The last week of life of nursing home residents with advanced dementia: a retrospective study
}

\author{
Franco Toscani', Silvia Finetti', Fabrizio Giunco ${ }^{2}$, Ines Basso ${ }^{3}$, Debora Rosa ${ }^{4}$, Francesca Pettenati ${ }^{1}$, \\ Alessandro Bussotti ${ }^{5}$, Daniele Villani ${ }^{6}$, Simona Gentile ${ }^{7}$, Lorenzo Boncinelli ${ }^{8}$, Massimo Monti ${ }^{9}$, Sandro Spinsanti ${ }^{10}$, \\ Massimo Piazza ${ }^{11}$, Lorena Charrier ${ }^{12^{*}}$ (D) and Paola Di Giulio ${ }^{12,13}$
}

\begin{abstract}
Background: Barriers to palliative care still exist in long-term care settings for older people, which can mean that people with advanced dementia may not receive of adequate palliative care in the last days of their life; instead, they may be exposed to aggressive and/or inappropriate treatments. The aim of this multicentre study was to assess the clinical interventions and care at end of life in a cohort of nursing home (NH) residents with advanced dementia in a large Italian region.
\end{abstract}

Methods: This retrospective study included a convenience sample of $29 \mathrm{NHs}$ in the Lombardy Region. Data were collected from the clinical records of 482 residents with advanced dementia, who had resided in the NH for at least 6 months before death, mainly focusing on the 7 days before death.

Results: Most residents (97.1\%) died in the NH. In the 7 days before death, 20\% were fed and hydrated by mouth, and $13.4 \%$ were tube fed. A median of five, often inappropriate, drugs were prescribed. Fifty-seven percent of residents had an acknowledgement of worsening condition recorded in their clinical records, a median of 4 days before death.

Conclusions: Full implementation of palliative care was not achieved in our study, possibly due to insufficient acknowledgement of the appropriateness of some drugs and interventions, and health professionals' lack of implementation of palliative interventions. Future studies should focus on how to improve care for $\mathrm{NH}$ residents.

Keywords: Nursing homes, Dementia, Palliative care

\section{Background}

Dementia is an incurable condition that causes a progressive decline in health, characterized by comorbidities, increased severity of physical and cognitive disabilities, acute conditions typical of frailty, the worsening of chronic comorbidities, and dementia-related events such as recurrence of infections and eating problems, all of which require specific palliative care strategies [1]. People with dementia can survive for years [2] and are usually cared for in residential facilities, in particular in nursing homes (NHs), which provide many or

\footnotetext{
* Correspondence: lorena.charrier@unito.it

${ }^{12}$ Department of Public Health and Pediatrics, University of Turin, Via Santena

5 bis, 10126 Turin, Italy

Full list of author information is available at the end of the article
}

all of the long-term care services they need until their death [3]. Thus, for most of their residents, NHs should be prepared and able to provide palliative care.

However, barriers to palliative care still exist in longterm care settings for older people [4], which can mean that people with advanced dementia may not receive adequate palliative care in the last days of their life; instead they may be exposed to aggressive and/or inappropriate treatments [5-7]. Lack of communication between health care professionals and family carers is a barrier to the implementation of palliative care as family carers may be reluctant to accept that their relative is in the dying phase [1]. However, the family's understanding of the disease progression and of the dying phase does not always guarantee the implementation of palliative care 
[8]. Other barriers are high staff turnover (especially nurses) [9]; limited number of nurses [10]; and lack of competence in palliative care [11, 12]. Important differences in palliative care delivery do exist across countries [13], and also among institutions within the same country [14]. Italian $\mathrm{NHs}$ differ widely in the number of beds they have, the services they offer, and their quality of care, but very few provide palliative care consultations $[6,15]$.

\section{Methods}

\section{Aim}

The aim of this multicentre study was to assess the clinical interventions and care at end of life in a cohort of $\mathrm{NH}$ residents with advanced dementia in a large Italian region.

\section{Study setting}

We used data from the Valuazione dell'Efficacia della Leniterapia nell'Alzheimer e Demenze (VELA Project) [16], which was conducted in collaboration with the Fondazione Italiana Leniterapia of Florence and the Lino Maestroni Palliative Medicine Research Foundation of Cremona. The aim of the VELA Project was to compare end-of-life care procedures provided to $\mathrm{NH}$ residents with advanced dementia in the Lombardy Region, and in the surrounding areas of Florence in the Tuscany Region, before and after a short educational intervention to improve palliative care. Due to regional differences in the organization of $\mathrm{NHs}$ and in the services provided to $\mathrm{NH}$ residents with dementia, here we present only data from the Lombardy Region.

In the Lombardy Region, accredited NHs have their own medical and nursing staff, with a regulatory requirement ratio of $\geq 901 \mathrm{~min} /$ week of care per resident [17]; these NHs may be defined as "skilled NHs". With few exceptions, there is at least one nurse with a bachelor's degree available per shift. NHs in the region may also rely on consultants (geriatricians, neurologists, physiatrists, etc.) and may employ psychologists, occupational therapists, physiotherapists, or other specialists. Out of a network of $34 \mathrm{NHs}$ in the Lombardy Region that participated in a previous study [15], 29 agreed to participate in the present study (number of beds per $\mathrm{NH}$ ranged from 40 to 714). To be included in the analysis, $\mathrm{NH}$ residents had to have a Functional Assessment Staging Tool (FAST) stage $27 \mathrm{c}$ (double incontinence; loss of all intelligible vocabulary; non-ambulatory) [18] and have resided in the $\mathrm{NH}$ for at least 6 months before death.

The study was approved by the ethics committee of Don Carlo Gnocchi Foundation of Milano on February 20, 2013; it started on April 1, 2013 and concluded on January 31, 2015. In this paper, we describe the 60 days before death, with a special focus on the last 7 days in the entire cohort (pre and post educational intervention) of NH residents. Due to the limited impact of the educational intervention [16], the two cohorts were merged.

\section{Data collection}

Trained monitors collected data from clinical records, nursing records, and drug data sheets on up to 20 residents in each of the 29 participating NHs. This information included demographic characteristics, major comorbidities, and cause of death, as well as presence of the following: a comprehensive evaluation of the severity of clinical conditions, advance care planning, a legal representative (guardian), do not resuscitate (DNR) and do not hospitalize (DNH) orders, $\mathrm{NH}$ resident's wishes about treatment and funeral dispositions, and any other advance directive (AD). Specific information was also collected on nutrition and hydration in the 60 and 7 days before death, as well as on dialysis, symptoms, tests and interventions administered such as endotracheal suctioning, hospitalizations and admissions to the emergency department, assessment of pain and discomfort, drugs prescribed (classified according to the Anatomical Therapeutic Chemical code) [19], and palliative sedation in the 7 days before death. Nutrition and hydration were classified by a panel of experts (including experts in palliative care, geriatrics, nursing, psychology, family medicine, and bioethics) as palliative-oriented nutrition if nutrition and/or hydration were given by mouth only, if nutrition by mouth was accompanied by comfort hydration (i.e. the administration of $<1000 \mathrm{ml}$ of fluids/day by subcutaneous hydration), if only subcutaneous hydration was used, or if no nutrition or hydration was provided at all [16]. Comfort hydration was seen as a compromise between the advisability to reduce water intake to improve comfort and reduce symptoms, and family members' expectations and beliefs about hydration [20]. Nutrition and hydration were classified as non-palliativeoriented nutrition if given by parenteral route, via nasogastric tube, or via percutaneous endoscopic gastrostomy at any point during the 7 days before death [16]. Drugs prescribed in the 7 days before death were collected from drug sheets. $\mathrm{NH}$ residents with missing drug sheets and those who were admitted to hospital or the emergency department in the 7 days before death were excluded from the analyses on drugs prescribed.

\section{Statistical analyses}

For categorical variables, data are shown as absolute and relative (\%) frequencies with 95\% confidence intervals (CIs). Mean and standard deviation or median and interquartile range (IQR), as appropriate, were calculated for continuous variables. All analyses were performed with Stata 14 (StataCorp., College Station, TX, USA). 


\section{Results}

A cohort of $482 \mathrm{NH}$ residents was recruited, $26.8 \%$ of whom had Alzheimer-type dementia. Overall, half of the residents had between five and eight comorbidities (median 6), and $25 \%$ had more than eight comorbidities (Table 1).

Almost all residents $(468,97.1 \%)$ died in the NHs (median age at death: 89 years, IQR 83.6-93.1), 69 (14.7\%) of them had a family member present during the last hours of life (this information was available for 358 residents). Cause of death was available for 374 (77.6\%) NH residents, 96 (25.7\%) of whom had dementia reported as the cause of death. Only one NH resident had a selfwritten $\mathrm{AD}$; in 19 (3.9\%) cases, a family member reported the NH resident's wishes; and 60 (12.4\%) residents had guardian. In six (1.2\%) cases, the family reported the resident's preference for cremation.

In the 60 days before death, $378(78.4 \%) \mathrm{NH}$ residents were fed only by mouth; 43 (8.9\%) were fed by mouth and intravenous or subcutaneous integration; and 43 (8.9\%) were tube fed; data where missing for the remaining 18 residents. During the 60 days before death, a new feeding tube was placed in $26 \mathrm{NH}$ residents (of the 63 with a feeding tube in the 7 days before death, 37 already had it at 60 days before death).

\section{7 days before death}

A substantial worsening of clinical conditions (sometimes defined as "terminal conditions") was recorded in the clinical records a median of 4 days (IQR 2-11) before death for 275 (57.1\%) NH residents, and the notification of impending death was recorded a median of 1 day before death (IQR 0-3) for 150 (31.1\%) residents. Advance care planning was drawn up for only $21 \mathrm{NH}$ residents (4.4\%) (median 15 days before death; IQR 541). Two $(0.4 \%) \mathrm{NH}$ residents had a DNR, seven had a DNH (1.5\%), and one NH resident had both.

Two hundred and nine residents' clinical records included a registration of discussions with families on the worsening of residents' conditions, which took place a median of 3 (IQR 1-7) days before death. Eighty-six of these records also reported a discussion with the family of decisions to be made, which took place a median of 6 (IQR 2-20) days before death.

After the exclusion of $13 \mathrm{NH}$ residents with missing information on nutrition and hydration, we observed

Table 1 Main characteristics of the 482 nursing home $(\mathrm{NH})$ residents with advanced dementia (Functional Assessment Staging Tool stage $\geq 7 \mathrm{c}$ )

\begin{tabular}{|c|c|c|c|}
\hline & $\mathrm{n}(n=482)$ & $\%$ & $95 \% \mathrm{Cl}^{\mathrm{b}}(\%)$ \\
\hline Sex Female & 365 & 75.7 & $71.9 ; 79.5$ \\
\hline \multicolumn{4}{|c|}{ Age at NH admission, years, median (IQR'): 84.1 (79-88.7) } \\
\hline \multicolumn{4}{|l|}{ Diagnosis of dementia } \\
\hline Alzheimer & 129 & 26.8 & $22.8 ; 30.7$ \\
\hline Not defined & 175 & 36.3 & $32.0 ; 40.6$ \\
\hline Vascular & 138 & 28.6 & $24.6 ; 32.7$ \\
\hline Mixed & 33 & 6.8 & $4.6 ; 9.1$ \\
\hline Lewy body & 7 & 1.5 & $0.4 ; 2.5$ \\
\hline \multicolumn{4}{|l|}{ Comorbidities } \\
\hline Genitourinary & 435 & 90.2 & $87.6 ; 92.9$ \\
\hline Musculoskeletal & 409 & 84.9 & $81.6 ; 88.0$ \\
\hline Gastrointestinal tract & 135 & 28.0 & $24.0 ; 32.0$ \\
\hline Peripheral and central nervous system & 314 & 65.1 & $60.9 ; 69.4$ \\
\hline Hypertension & 238 & 49.4 & $44.9 ; 53.8$ \\
\hline Cardiovascular & 237 & 49.2 & $44.7 ; 53.6$ \\
\hline Head and neck & 207 & 42.9 & $38.5 ; 47.4$ \\
\hline Vascular & 195 & 40.5 & $36.1 ; 44.8$ \\
\hline Respiratory & 100 & 20.7 & $17.2 ; 24.4$ \\
\hline Endocrine-metabolic & 135 & 28.0 & $24.0 ; 32.0$ \\
\hline Kidney & 55 & 11.4 & $8.6 ; 14.2$ \\
\hline Liver & 30 & 6.2 & $4.1 ; 8.4$ \\
\hline Others $^{\mathrm{a}}$ & 18 & 3.7 & $2.0 ; 5.4$ \\
\hline
\end{tabular}

${ }^{\mathrm{a}}$ Others: other cancers [15]; anemia [2]; pressure sores [1]

${ }^{\mathrm{b}} \mathrm{Cl}$ Confidence interval, IQR Interquartile range 
palliative-oriented nutrition in $130(27.7 \%)$ residents (Table 2).

Overall, $101 \mathrm{NH}$ residents (21\%) received at least one invasive treatment or intervention in the 7 days before death (Table 3).

In the 7 days before death, nine residents were sent to the emergency department and then discharged, while 14 were admitted to hospital (2.9\%). Pain and/or discomfort were assessed for 192 (39.8\%) residents. In 13 (2.7\%) cases, palliative pharmacological sedation was provided; 70 residents (14.5\%) underwent resuscitation attempts, 62 of which were performed by $\mathrm{NH}$ staff: five as cardio-pulmonary resuscitation, and 66 with lifesaving drugs.

Data on drugs prescribed were available for 316 (65.6\%) NH residents; a median of five (IQR 3-7) drugs were prescribed for these residents in the 7 days before death, and $22.2 \% \mathrm{NH}$ residents had two or fewer drugs prescribed (Table 4).

\section{Discussion}

This study presents data on a large cohort of $\mathrm{NH}$ residents with advanced dementia who died in a $\mathrm{NH}$ located in a large region of northern Italy. In contrast to previous studies, in which one-third of $\mathrm{NH}$ residents were hospitalized in the last month of life and the rate of death in hospital was almost $66 \%$ [21, 22], the vast majority of our residents died in the NHs: only $4.7 \%$ of them were admitted to hospital or sent to the emergency department. This low figure may be considered positive, as hospitalization can be aggressive and of limited clinical benefit for people with advanced dementia [23]. The availability of a full-time physician, and the fact that all $\mathrm{NHs}$ that participated in the present analysis are skilled NHs, may account for this result.

In general, although the care received by $\mathrm{NH}$ residents with advanced dementia in the 7 days before death showed room for improvement, it also showed a preference for non-aggressive treatment. Sixty days before death, the vast majority of $\mathrm{NH}$ residents (78.4\%) were fed only by mouth, but, as expected, that number decreased to nearly one in five $(20 \%)$ in the 7 days before

Table 2 Nutrition and hydration in the 7 days before death

\begin{tabular}{llll}
\hline & $\mathrm{n}(n=469)^{\mathrm{b}}$ & $\%$ & $95 \% \mathrm{Cl}^{\mathrm{a}}(\%)$ \\
\hline IV $^{\mathrm{a}}$ hydration (alone or supplement) & 227 & 48.4 & $43.9 ; 52.9$ \\
Nutrition/hydration by mouth only & 94 & 20.0 & $16.4 ; 23.7$ \\
SFA $^{\mathrm{a}}$ only (or SFA+ mouth) & 70 & 14.9 & $11.7 ; 18.1$ \\
Tube feeding & 63 & 13.4 & $10.3 ; 16.5$ \\
Parenteral Nutrition & 15 & 3.2 & $1.6 ; 4.8$ \\
Comfort hydration (IV and SFA) & $99 / 455$ & 21.8 & $18.0 ; 25.5$ \\
\hline
\end{tabular}

${ }^{a} \mathrm{Cl}$ Confidence interval, IV Intravenous, SFA Subcutaneous fluids administration

${ }^{\mathrm{b}} 13$ residents with missing information on nutrition and hydration death. Overall, one-third of $\mathrm{NH}$ residents received palliative-oriented nutrition in the 7 days before death. It is broadly acknowledged that tube feeding in people with advanced dementia is ineffective and even harmful, and that possible symptoms of dehydration can be effectively treated with small amounts of fluids (by mouth or by subcutaneous fluids administration) with good oral care [24]. Nevertheless, relatives often ask for substantial nutrition and hydration [25]. The limited use of subcutaneous fluids administration in our study could be ascribed to a lack of knowledge of this technique on the part of NH staff [26].

The figures we report related to feeding tubes, namely the number of patients who died with a feeding tube in place, are higher than those reported in a Dutch [27] and a US study, which showed a decrease in tube feeding over 15 years (from $11.7 \%$ in 2000 to $5.7 \%$ in 2014) [28]. Nevertheless, our results reflect a substantial positive trend when compared with the findings of a previous study (tube feeding $21.0 \%$ vs tube feeding and parenteral nutrition 16.6\%; intravenous hydration $66 \%$ vs $48.4 \%$ ) carried out in 2005 in a smaller sample of $\mathrm{NHs}$ in the same region [5]. The same trend toward a less aggressive approach was shown by the decreased use of intravenous fluid administration (from 67\% to nearly 40\%) [6]. Further positive findings from our study concern the use of drugs, with the increased use of opioids (from $4.9 \%$ at baseline [29] to $34.2 \%$ in the 7 days before death) and acetaminophen (from 4.5\% [29] to 7.6\%); the low rate of blood samples taken (less than 2 patients out of 10); and the low rate of other invasive treatments/interventions.

Some aspects still require closer scrutiny and improvement, in particular clinical factors. For example, the prescribing of inappropriate drugs $[30,31]$, such as anticoagulants/antiplatelets and anti-arrhythmics classes I-III, continued in our study. Moreover, diuretics, betablocking agents, antipsychotics, and antibiotics, even if considered "sometimes appropriate", seemed to be overly prescribed in the last 7 days before death (hyoscine, steroids, and antacids may have been prescribed as symptomatics). There was also an overuse of procedures like intravenous catheter placement and an underuse of subcutaneous fluids administration.

The acknowledgement of the worsening of resident's conditions was reported in the clinical records of $57 \%$ of $\mathrm{NH}$ residents a few days before death (median 4), but only 21 of these residents had a care plan in place. Lastly, considering the residents' advanced stage of dementia, some questionable resuscitation attempts were carried out (14.5\%, mostly with drugs). The trajectories of decline in persons with dementia are uncertain [32]; therefore it is not easy to assess when a resident is approaching death. If the proximity of death is only acknowledged when a resident's health condition rapidly 
Table 3 Invasive treatments/interventions in the 7 days before death

\begin{tabular}{llll}
\hline & $\mathrm{n}(n=482)$ & $\%$ & 21.0 \\
\hline Oral/tracheal suctioning & 101 & 15.1 & $17.3 ; 24.6$ \\
Blood collection & 73 & 11.0 & $11.9 ; 18.3$ \\
Peripheral vein cannulation (one or more attempts) & 53 & 6.2 & $8.2 ; 13.8$ \\
Insertion/repositioning of urinary catheter & 30 & 2.3 & $4.1 ; 8.4$ \\
Insertion/repositioning of a nasogastric tube (2 PEGs $\left.{ }^{\mathrm{b}}\right)$ & 11 & 0.6 & $0.9 ; 3.6$ \\
Insertion of a central venous catheter $^{\text {Other invasive treatments }}{ }^{\mathrm{a}}$ & 3 & 1.2 & $0.0 ; 1.3$ \\
\hline
\end{tabular}

${ }^{a}$ Other treatments (residents could be exposed to more than one treatment): Enema [2]; Glycaemia measurement [2]; Hemogasanalysis [1]; Flu vaccine [1]

${ }^{\mathrm{b}} \mathrm{Cl}$ Confidence interval, PEG Percutaneous endoscopic gastrostomy

declines [33], fewer opportunities are left to provide palliative care and hospice referral [34]. The difficulty of defining terminality, and of reliably estimating survival in people with advanced dementia requires structured investments to produce effective tools to identify and evaluate these factors [35]. These findings also show the need to improve the knowledge of $\mathrm{NH}$ staff, including physicians, on these issues [16]. This need is reflected in the urgency placed on national regulatory bodies and international scientific boards to produce up-to-date, widely accepted guidelines on the appropriate pharmacological approach to take in patients with dementia who are at the end of their life $[7,30]$.

Table 4 Prescriptions in the 7 days before death classified according to the Anatomical Therapeutic Chemical (ATC) code

\begin{tabular}{|c|c|c|c|c|}
\hline & ATC code & $\mathrm{n}(n=316)$ & $\%$ & $95 \% \mathrm{Cl}^{\mathrm{b}}(\%)$ \\
\hline Anticoagulants - Antiplatelets & B01A & 166 & 52.5 & $47.0 ; 58.0$ \\
\hline Drugs for acid related disorders & A02 & 153 & 48.4 & $42.9 ; 53.9$ \\
\hline Cardiovascular System & C & & & \\
\hline Cardiac therapy & C01A, C01D & 130 & 41.1 & $35.7 ; 46.6$ \\
\hline Beta blocking agents & $\mathrm{CO7}$ & 31 & 9.8 & $6.5 ; 13.1$ \\
\hline Anti-arrhythmic class I-III & C01B & 8 & 2.5 & $0.8 ; 4.2$ \\
\hline Antibiotics (antibacterial/antimycotics) & $\mathrm{J} 01 ; \mathrm{J} 02$ & 107 & 33.9 & $28.6 ; 39.1$ \\
\hline Diuretics & $\mathrm{CO3}$ & 110 & 34.8 & $29.5 ; 40.1$ \\
\hline Opioids & $\mathrm{N} 02 \mathrm{~A}$ & 108 & 34.2 & $28.9 ; 39.4$ \\
\hline Laxatives & A06 & 96 & 30.4 & $25.3 ; 35.4$ \\
\hline Vitamins and mineral supplements & $\mathrm{A} 11 ; \mathrm{A} 12$ & 88 & 27.8 & $22.9 ; 32.8$ \\
\hline Antipsychotics & N05A & 79 & 25.0 & $20.2 ; 29.8$ \\
\hline Benzodiazepine derivates & N05CD & 70 & 22.2 & $17.6 ; 26.7$ \\
\hline Steroids & $\mathrm{H} 02 \mathrm{AB}$ & 58 & 18.4 & $14.1 ; 22.6$ \\
\hline Drugs for the respiratory system & R & 37 & 11.7 & $8.2 ; 15.2$ \\
\hline Antiepileptics & N03 & 30 & 9.5 & $6.3 ; 12.7$ \\
\hline Insulin and other glucose lowering & $\mathrm{A} 10$ & 27 & 8.5 & $5.5 ; 11.6$ \\
\hline Acetaminophen & $\mathrm{N} 02 \mathrm{~B}$ & 24 & 7.6 & $4.7 ; 10.5$ \\
\hline Antidepressants & N06 & 24 & 7.6 & $4.7 ; 10.5$ \\
\hline Anti-parkinson & N04 & 23 & 7.3 & $4.4 ; 10.1$ \\
\hline Antiemetics & $\mathrm{A} 04$ & 19 & 6.0 & $3.4 ; 8.6$ \\
\hline Hyoscine Butylbromide & N07 & 14 & 4.4 & $2.2 ; 6.7$ \\
\hline Thyroid drugs & $\mathrm{H} 03$ & 17 & 5.4 & $2.9 ; 7.9$ \\
\hline Others $^{a}$ & & 29 & 9.2 & $6.0 ; 12.4$ \\
\hline
\end{tabular}

OOthers: Allopurinol (M04 11), Drugs for benign prostatic hypertrophy (Tam/usosin, Finasteride (G04 AC, 10), Antidiarrhoics (A07, 5), Ursodesooxyicholic acid (A05AA02 4), Drugs for treatment of hyperkaliemia and hyperphosphatemia (V03AE, 3), Hormone antagonists (L02, 2), Baclofen (M03BX, 2); only 1: Epoietine (B03); Rociverine (A03AA)

${ }^{\mathrm{b}} \mathrm{Cl}$ Confidence interval 
Critical decisions also require closer scrutiny and improvement. One of the most disappointing findings was the extremely low presence of ADs, whether they were self-written or communicated by relatives, and the scarcity of guardians and/or surrogates. In Italy, the legal representative must be appointed by a magistrate, generally at the request of the health care provider (e.g., general practitioner and/or the $\mathrm{NH}$ doctor), and this procedure can take some time. This may explain the scarcity of DNR and/or DNH orders in our study (overall $8 \mathrm{NH}$ residents) and even the use of palliative pharmacological sedation. DNR and DNH orders are far more common in other European countries: $2.4 \%$ in our study, compared to $21.0 \%$ in Holland [36] and $60 \%$ in the US [37].

Family involvement in decisions was documented in only 86 clinical records, and a recent study reported that most decisions are first taken by the physicians and only later communicated to relatives [15]. The low prevalence of advance care planning suggests a tendency to avoid addressing the issue with family [38], and efforts should be made to improve this. Advance care planning implies the involvement of family, in what have been called "expectation conversations" [39]. Only $3.4 \%$ of $\mathrm{NH}$ residents were involved in conversations on desired end-of-life care in the van der Voot et al. study [36] (although more than $60 \%$ were cognitively competent at admission), and even if $\mathrm{NH}$ staff say they are available to speak with $\mathrm{NH}$ residents' relatives about death and dying when they are "terminal" [38], systematic, periodic conversations with families are a crucial instrument to reducing $\mathrm{NH}$ staff's uncertainty in clinical decisionmaking and to improve the family's perceptions of quality of care in NHs [39, 40].

Critical decisions may affect the time of death, the place of death [33], and the way a person will live her/ his last days. If a patient is incapacitated and there is no surrogate and/or $\mathrm{ADs}$, the ultimate responsibility for treatment decisions falls on the physician, whose decisions may be affected by several factors, such as the context (setting and culture) [41], personal and societal values and constraints, and medical training that is overly focused on curing $[15,42]$. A framework that shares this planning with the family may reduce the temptation to revert to the use of defensive medicine (i.e., practices undertaken primarily to avoid liability rather than to benefit the patient), which may be partially responsible for resuscitation attempts, placement of feeding tubes [25], the drawing of blood samples, the avoidance of writing DNR/DNH orders, etc. This behavior implies that, in spite of the spread and seeming acceptance of the principles and methods of palliative care, at least in NHs, prejudices and fears persist.
Our results are limited by the retrospective nature of the study and by data retrieval from clinical records; some aspects such as relatives' involvement in decisions may have been under-reported. Although this is a multicentre study, each $\mathrm{NH}$ contributed the same number of cases, thus limiting the possible over-representation of residents from larger NHs. Data were collected by expert, trained researchers, which may have limited interpretation problems.

\section{Conclusions}

Notwithstanding some clear improvements in the quality of palliative care, which reflects a positive trend toward a less aggressive approach to treatment among $\mathrm{NH}$ residents with advanced dementia in their last days of life, there are still some barriers to a full implementation of palliative care. In particular, insufficient acknowledgement of the inappropriateness of some drugs and interventions, and reluctance to implement end-of-life palliative care interventions. In order to provide quality palliative care to $\mathrm{NH}$ residents with advanced dementia, up-to-date, widely accepted guidelines on the pharmacological approach to take in patients with advanced dementia are urgently needed. At the same time, changes in the cultural approach to death and dying are necessary in $\mathrm{NH}$ staff and the general population if clinically correct care strategies are to be outlined that can be agreed upon by $\mathrm{NH}$ residents and their families.

\section{Abbreviations \\ AD: Advance directive; ATC: Anatomical Therapeutic Chemical; Cl: Confidence interval; DNH: Do not hospitalize; DNR: Do not resuscitate; FAST: Functional Assessment Staging Tool; IQR: Interquartile range; IV: Intravenous; NH: Nursing home; PEG: Percutaneous endoscopic gastrostomy; SFA: Subcutaneous fluids administration; VELA: Valutazione dell'Efficacia della Leniterapia nell'Alzheimer e Demenze}

\section{Acknowledgements}

We are grateful to the nursing homes that took part in this study, to Nicola Casanova and Serena Bassi of the File Foundation for their support in the organization of the project, to Mauro Bosio for administrative and financial management, to Andrea Vannucci of the Health Authority of Florence for easing the project in the Tuscany Region and to Trudy Perdrix-Thoma for English language editing.

\section{Authors' contributions}

All authors meet the criteria for authorship stated in the Uniform Requirements for Manuscripts Submitted to Biomedical Journals. Concept or design of the work, FT, PDG. Acquisition, analysis or interpretation of data; SF, LC, IB, FP, DR. Draft of the article, FT, PDG, LC. Critical revision of the article, FT, PDG, LC, IB, FG, AB, DV. SG, LB, MM, SS, MP. Approval of version to be published, All.

\section{Funding}

The V.E.L.A. project was funded by grants of the Foundation Cassa di Risparmio delle province Lombarde (Grant 2011/1515) and of the Foudation Cassa di Risparmio di Firenze. The sponsors had no role in the design of the study, data collection, analyses and interpretation of the results.

\section{Availability of data and materials}

The datasets used and/or analyzed during the current study are available from the corresponding author on reasonable request. 


\section{Ethics approval and consent to participate}

The study was approved by the Ethic committee of Don Carlo Gnocchi Foundation of Milano on February 20, 2013.

\section{Consent for publication}

Not applicable.

\section{Competing interests}

The authors declare that they have no competing interests.

\section{Author details}

'Lino Maestroni Foundation, Palliative Medicine Research Institute, via Palestro 1, 26100 Cremona, Italy. ${ }^{2}$ Department of Health and Social Services Polo Lombardia 2, Don Carlo Gnocchi Foundation ONLUS, Via Palazzolo, 21, 20149 Milan, Italy. ${ }^{3}$ Intensive Care Unit, SS Antonio e Biagio e Cesare Arrigo Hospital, Via Venezia, 16, 15121 Alessandria, Italy. ${ }^{4}$ University of Milan, section of Don Carlo Gnocchi Foundation, Via A. Capecelatro, 66, 20148 Milan, Italy. ${ }^{5}$ Agenzia Continuità Ospedale Territorio, Azienda Ospedaliero- Universitaria Careggi, Largo Brambilla 3, 50134 Florence, Italy. ${ }^{6}$ Neuro-Rehabilitation and Alzheimer Disease Evaluation Unit, Figlie di San Camillo Hospital, Via F. Filzi , 56, 26100 Cremona, Italy. ${ }^{7}$ Rehabilitation and Alzheimer Disease Evaluation Unit, Ancelle della Carità Hospital, Via G. Aselli, 14 Cremona, Italy. ${ }^{8}$ Intensive Care Unit Geriatric, AOU Careggi-Largo Brambilla,3, 50134 Florence, Italy. ${ }^{9}$ Geriatric Institute Pio Albergo Trivulzio, via Trivulzio, 15, 20146 Milan, Italy. ${ }^{10}$ Istituto Giano, Via Stazzo Quadro 7, 00060 Riano (Rm), Milan, Italy. ${ }^{11}$ Italian Foundation of Leniterapia (FILE), Via San Niccolò, 1, 50125 Florence, Italy.

${ }^{12}$ Department of Public Health and Pediatrics, University of Turin, Via Santena 5 bis, 10126 Turin, Italy. ${ }^{13}$ SUPSI, Manno, Switzerland.

Received: 12 July 2019 Accepted: 19 December 2019

Published online: 27 December 2019

\section{References}

1. van der Steen JT, Radbruch L, Hertogh CM, de Boer ME, Hughes JC, Larkin $P$, et al. White paper defining optimal palliative care in older people with dementia: a Delphi study and recommendations from the European Association for Palliative Care. Palliat Med. 2014;28:197-209.

2. Todd S, Barr S, Roberts M, Passmore AP. Survival in dementia and predictors of mortality: a review. Int J Geriatr Psychiatry. 2013;28:1109-24.

3. Mitchell SL, Teno JM, Miller SC, Mor V. A national study of the location of death for older persons with dementia. J Am Geriatr Soc. 2005;53:299-305.

4. Fosse A, Zuidema S, Boersma F, Malterud K, Schaufel MA, Ruths S. Nursing home physicians' assessments of barriers and strategies for end-of-life care in Norway and the Netherlands. J Am Med Dir Assoc. 2017;18:713-8.

5. Davies E, Higginson IJ. Better palliative care for older people. Copenhagen: WHO Regional Office for Europe; 2004. http://www.euro.who.int/_data/ assets/pdf file/0009/98235/E82933.pdf. Accessed 27 Nov 2019

6. Di Giulio P, Toscani F, Villani D, Brunelli C, Gentile S, Spadin P. Dying with advanced dementia in long-term care geriatric institutions: a retrospective study. J Palliat Med. 2008;11:1023-8.

7. Toscani F. Prescribing in palliative care: a quest for appropriateness. Palliat Med. 2013;27:293.

8. Vandervoort A, Houttekier D, Vander Stichele R, van der Steen JT, Van den Block L. Quality of dying in nursing home residents dying with dementia: does advanced care planning matter? A nationwide postmortem study. PLoS One. 2014;9:e91130.

9. Tilden VP, Thompson SA, Gajewski BJ, Bott MJ. End-of-life care in nursing homes: the high costs of staff turnover. Nurs Econ. 2012:30:163-6.

10. Anstey S, Powell T, Coles B, Hale R, Gould D. Education and training to enhance end-of -life care for nursing home staff: a systematic literature review. BMJ Support Pall Care. 2016;6:353-61.

11. Brazil K, Brink P, Kaasalainen S, Kelly ML, McAiney C. Knowledge and perceived competence among nurses caring for the dying in long-term care homes. Int J Palliat Nurs. 2012;18:77-83.

12. Albers G, Froggatt $K$, Van den Block L, Gambassi G, Vanden Berghe $P$, Pautex S, et al. EURO -IMPACT. A qualitative exploration of the collaborative working between palliative care and geriatric medicine: barriers and facilitators from a European perspective. BMC Palliat Care. 2016;15:47.

13. van der Steen JT, Kruse RL, Ooms ME, Ribbe MW, van der Wal G, Heintz LL, et al. Treatment of nursing home residents with dementia and lower respiratory tract infection in the United States and the Netherlands: an ocean apart. J Am Geriatr Soc. 2004;52:691-9.

14. Teno JM, Mitchell SL, Kuo SK, Gozalo PL, Rhodes RL, Lima JC, et al. Decision making outcomes of feeding tube insertion: a five-state study. J Am Geriatr Soc. 2011;59:881-6.

15. Toscani F, van der Steen JT, Finetti S, Giunco F, Pettenati F, Villani D, et al. End of Life Observatory-Prospective Study on DEmentia Patients Care (EoLO-PSODEC) Research Group. Critical decisions for older people with advanced dementia: a prospective study in long-term Institutions and district home care. J Am Med Dir Assoc. 2015;16:535.e13-20.

16. Di Giulio P, Finetti S, Giunco F, Basso I, Rosa D, Pettenati F, et al. The impact of nursing homes staff education on end-of-life care in residents with advanced dementia: a quality improvement study. J Pain Symptom Manag. 2019;57:93-9.

17. Regione Lombardia, Bollettino Ufficiale - Milano, 2003: Requisiti di Accreditamento, p1269 2003 http://www.terzaeta.com/database/leggi-edecreti-regionali/lombardia/burl2003_16rsa.pdf. Accessed 27 Nov 2019.

18. Sclan SG, Reisberg B. Functional assessment staging (FAST) in Alzheimer's disease: Reliability, validity, and ordinality. Int Psychogeriatr. 1992;4(Suppl 1):55-69.

19. WHO Collaborating Centre for Drug Statistics Methodology, Guidelines for ATC Classification and DDD Assignment 2010. https://www.whocc.no/ filearchive/publications/2019_guidelines_web.pdf. Accessed 27 Nov 2019.

20. Cohen MZ, Torres-Vigil I, Burbach BE, de la Rosa A, Bruera E. The meaning of parenteral hydration to family caregivers and patients with advanced cancer receiving hospice care. J Pain Symptom Manag. 2012;43:855-65.

21. Miller SC, Lima JC, Thompson SA. End-of-Life Care in Nursing Homes with Greater versus Less Palliative Care Knowledge and Practice. J Palliat Med. 2015:18:527-34.

22. Nicholas LH, Bynum JP, Iwashyna TJ, Weir DR, Langa KM. Advance directives and nursing home stays associated with less aggressive end-of-life care for patients with severe dementia. Health Aff (Millwood). 2014;33:667-74

23. Mitchell SL, Black BS, Ersek M, Hanson LC, Miller SC, Sachs GA, et al. Advanced dementia: state of the art and priorities for the next decade. Ann Intern Med. 2012;156:45-51.

24. McCann RM, Hall WJ, Growth-Junker A. Comfort care for terminally ill patients receiving i.v. hydration. JAMA. 1994:8:45-9.

25. Ying I. Artificial nutrition and hydration in advanced dementia. Can Fam Physician. 2015:61:245-8.

26. Brugnolli A, Bevilacqua A, Clodig M, Danielis M. Idratazione con ipodermoclisi nel paziente anziano. Assist Inferm Ric. 2012;31:145-50.

27. Hendriks SA, Smalbrugge M, Deliens L, Koopmans RTCM, OnwuteakaPhilipsen BD, Hertogh CMPM, et al. End-of-life treatment decisions in nursing home residents dying with dementia in the Netherlands. Int J Geriatr Psychiatry. 2017;32:e43-9.

28. Mitchell SL, Mor V, Gozalo PL, Servadio JL, Teno JM. Tube feeding in US nursing home residents with advanced dementia, 2000-2014. JAMA. 2016; 316:769-70

29. Toscani F, Di Giulio P, Villani D, Giunco F, Brunelli C, Gentile S, on behalf of the End of Life Observatory - Prospective Study on DEmentia Patients Care (EoLO-PSODEC) Research Group, et al. Treatments and prescriptions in advanced dementia patients residing in long-term care institutions and at home. J Palliat Med. 2013;16:31-7.

30. Holmes HM, Hayley DC, Alexander GC, Sachs GA. Reconsidering medication appropriateness for patients late in life. Arch Intern Med. 2006;166:605-9.

31. Holmes HM, Sachs GA, Shega JW, Hougham GW, Cox Hayley D, Dale W. Integrating palliative medicine into the care of persons with advanced dementia: identifying appropriate medications use. J Am Geriatr Soc. 2008; 56:1306-11.

32. Barclay S, Froggatt K, Crang C, Mathie E, Handley M, Iliffe S, et al. Living in uncertain times: trajectories to death in residential care homes. Br J Gen Pract. 2014;64(626):e576-83.

33. Teno JM, Casarett D, Spence C, Connor S. It is "too late" or is it? Bereaved family member perceptions of hospice referral when their family member was on hospice for seven days or less. J Pain Symptom Manag. 2012;43: 732-8.

34. Mitchell SL, Teno JM, Kiely DK, Shaffer ML, Jones RN, Prigerson HG, et al. The clinical course of advanced dementia. N Engl J Med. 2009;36:1529-38.

35. Mitchell SL, Shaffer ML, Cohen S, Hanson LC, Habtemariam D, Volandes AE. An advance care planning video decision support tool for nursing home residents with advanced dementia. A cluster randomized clinical trial. JAMA Intern Med. 2018;187:961-9. 
36. Vandervoort A, Houttekier D, Van den Block L, van der Steen JT, Vander Stichele R, Deliens L. Advance care planning and physician orders in nursing home residents with dementia: a nationwide retrospective study among professional caregivers and relatives. J Pain Symptom Manag. 2014:47:245-56.

37. Tjia J, Dharmawardene M, Givens JL. Advance directives among nursing home residents with mild, moderate, and advanced dementia. J Palliat Med. 2018;21:16-21.

38. Johnson S, Bott MJ. Communication with Residents and Families in Nursing Homes at the End of Life. J Hosp Palliat Nurs. 2016;18:124-30.

39. Levy C. Expectation conversations about the very predictable events in advanced dementia. J Am Dir Associat. 2015;16:724-7.

40. Brazil K, Carter G, Cardwell C, Clarke M, Hudson P, Froggatt K, et al. Effectiveness of advance care planning with family carers in dementia nursing homes: a paired cluster randomized controlled trial. Palliat Med. 2018:32:603-12.

41. Lynn J, Arkes HR, Stevens M, Cohn F, Koenig B, Fox E, et al. Rethinking fundamental assumptions: SUPPORT's implications for future reform. Study to understand prognoses and preferences and risks of treatment. J Am Geriatr Soc. 2000;48:S214-21.

42. Helton MR, van der Steen JT, Daaleman TP, Gamble GR, Ribbe MW. A crosscultural study of physician treatment decisions for demented nursing home patients who develop pneumonia. Ann Fam Med. 2006:4:221-7.

\section{Publisher's Note}

Springer Nature remains neutral with regard to jurisdictional claims in published maps and institutional affiliations.

Ready to submit your research? Choose BMC and benefit from:

- fast, convenient online submission

- thorough peer review by experienced researchers in your field

- rapid publication on acceptance

- support for research data, including large and complex data types

- gold Open Access which fosters wider collaboration and increased citations

- maximum visibility for your research: over $100 \mathrm{M}$ website views per year

At BMC, research is always in progress.

Learn more biomedcentral.com/submissions 